\title{
Microscopic Identification of Progressive Fracturing in Granite Under Triaxial and Uniaxial Stress Conditions from Bátaapáti Radwaste Repository
}

\author{
Ferenc Deák ${ }^{1,2^{*}}$, László Kovács³ ${ }^{3}$ Péter Mucsi ${ }^{1}$ Zoltán Máthé ${ }^{1}$ \\ ${ }^{1}$ Mecsekérc Ltd., H-7633 Pécs, Esztergár Lajos str. 19, Hungary, \\ 2 Faculty of Engineering Geology and Geotechnics, Budapest University of Technology and Economics, H-1521 Budapest, P.O.B. 91 , \\ Hungary, \\ ${ }^{3}$ RockStudy Ltd., H-7633 Pécs, Esztergár Lajos str. 19, Hungary \\ * Corresponding author, e-mail: deakferenc@mecsekerc.hu
}

Received: 14 November 2019, Accepted: 09 January 2020, Published online: 10 February 2020

\begin{abstract}
The program for the final disposal of low and intermediate level radioactive waste was established by Paks Nuclear Power Plant, Hungary. Preparation of final disposal has been done as part of a national program since 1993. The Central Nuclear Financial Fund and the Public Limited Company for Radioactive Waste Management (PURAM) have been established to coordinate organizations and activities for all tasks in connection, with nuclear waste treatment. The project was started with a geological screening in order to find the most suitable geological formation for a radioactive waste repository. The selected potential host rock is the Mórágy Granite Formation in the south-western part of Hungary, close to the village of Bátaapáti.

This paper show and explain the results of an extensive study of the deformation and fracturing of Mórágy granite samples under uniaxial and triaxial loading conditions. In the investigation, the stress fracturing thresholds (crack initiation, crack coalescence and crack damage) were determined using stress-strain and stiffness curves without acoustic emission (AE) detection technique. Crack initiation was found to be best determined by the volumetric strain curve in both uniaxial and triaxial compression tests. As a detailed investigation, a comprehensive petrographical analysis using a petrological microscope was performed to identify the mode of cracking and the characterization of the cracking pattern.
\end{abstract}

Keywords

brittle fracturing, uniaxial loading, triaxial loading, failure thresholds, petrological microscopy

\section{Introduction}

In rock mass and rock samples the existing fractures tend to close as the stress increases. The mentioned closure of the existing fractures in the rock brings the failure brittle.

By opening underground spaces in a stressed rock mass results in the deformation of the near-field rock due to a redistribution of stresses, resulting in induced stress concentrations. This stress redistribution increases strain energy in zones of increased compression. The high induced compressive stresses around a deep opening result in the initiation and propagation of stress-induced fractures parallel to the excavation boundary. Accordingly, it is important to establish the thresholds associated with microscale and macroscale fracturing in the in-situ rock mass.

The deformation and fracture characteristics of brittle rocks have been studied by numerous researchers over the past decades. Among the proposed fundamental concepts of rock fracture, Griffith's theory [1] in elastic materials is the fundamental concept on which past and present research has been based. A Griffith's crack is a flaw which is approximately elliptical in shape. It is assumed that the fracture initiates from the boundary of an open flaw when the tensile stress on this boundary exceeds the local tensile strength of the material. Griffith's cracking scenario was later modified to account for the frictional effects due to crack closure in compression by McClintock and Walsh [2]. Brace [3] and Bieniawski [4] later proposed the generally-accepted concept of a brittle rock failure mechanism, which extensively describes the brittle failure process as crack closure, crack initiation and crack propagation leading to failure. Brace and Bombolakis [5] 
and Hoek and Bieniawski [6] have demonstrated experimentally that a crack which initiates on the boundary of the elliptical flaw propagates out of the plane of this flaw. Hoek [7] summarized the early research on brittle fracture behaviour of hard rock by Griffith [1]. Moreover, Hoek [7] showed that since a fracture is assumed to occur when the tangential stress on the boundary of the flaw exceeds the local tensile strength of the material, it can be assumed that the crack will propagate in a direction which is normal to the boundary of the ellipse. It is strongly believed that the micro-cracking mechanism is initiated from preexisting cracks in rock which lead to macro-cracking failure. The initiation and propagation of cracks generate elastic waves in conjunction with energy release called acoustic emissions. Therefore, the study of acoustic emission (AE) allows the identification of the characteristics and correlates with the fracture mechanism. Lajtai and Lajtai [8], Reyes and Einstein [9] and Bobet and Einstein [11] have studied extensively the cracking patterns of overlapping and non-overlapping flaws in gypsum plaster under confined and unconfined compression.

Griffith's theory was further supported by the studies by Reyes and Einstein [9], Shen [10] and Bobet and Einstein [11], who observed two types of crack patternsi.e., primary and secondary cracks in pre-existing fractures in gypsum specimens loaded in uniaxial and biaxial compression. However, as Brady and Brown [12] commented, the use of Griffith's microscopic theory to predict the macroscopic behaviour of rock material under a variety of boundary conditions requires the introduction of a set of Griffith crack size, shape and orientation distribution functions which have not yet been defined. The main objective of the present study is to investigate the deformation and strength characteristics and the fracturing characteristics of Mórágy Granite Formation (MGF) granite, under static loading conditions, in order to better understand the behavior of the rock around underground caverns.

\section{Geological background}

The investigated samples were collected from the National Radioactive Waste Repository (Low and Intermediatelevel Wastes) beside the village of Bátaapáti [13], which in geographically part of the Eastern-Mecsek Mountains, and in geological terms part of the NE Mórágy Crystalline Block. The area represents a part of the so-called MecsekZone as the northern element of the Tisza Unit [14]. The block is bordered by approx. 750-1000 m wide, socalled Mecsekalja Dislocation Zone from the direction of
NE and Triassic-Jurassic successions from North. Lower Miocen and Pannonian beds (sandstones, conglomerates, marls) have been deposited at the margins of the MGF (Figs. 1 and 2). This crystalline basement has been covered by Pleistocene and Holocene deposits (loess, red clays, fluvial complex) $[15,16]$.

The rocks of the MGF were formed by mixing of felsic and mafic magmas resulted the amfibol and quartz monzonite contains enclaves that are the relics of this magma mixing [17]. Beside that leucocratic dykes are crosscut both of the granitoid rocks and their enclaves. The rock types are the following: monzogranite, mafic enclaves (monzonite, syenite, and diorite), and leucocratic dykes with aplites.

The structural evolution of the Mórágy Granite is quite complex [18]:

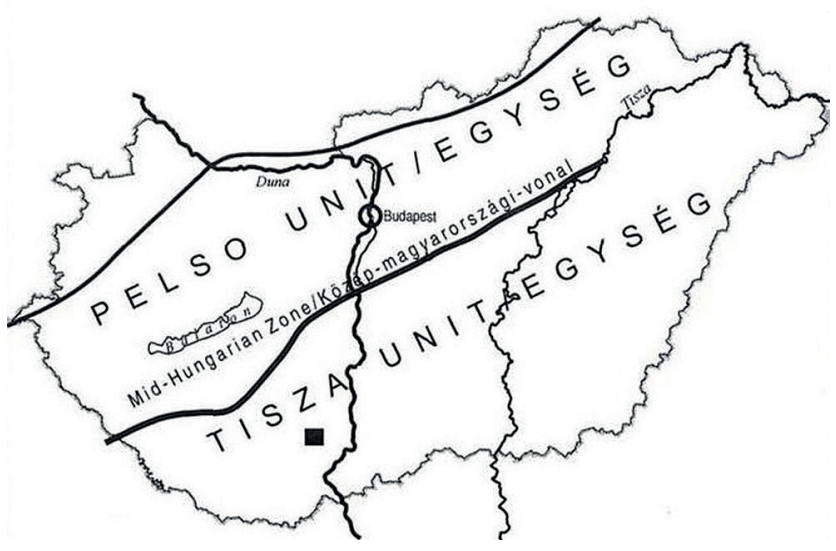

Fig. 1 Generalized structural geologic map of Hungary - the black square is showing the investigated site [19]

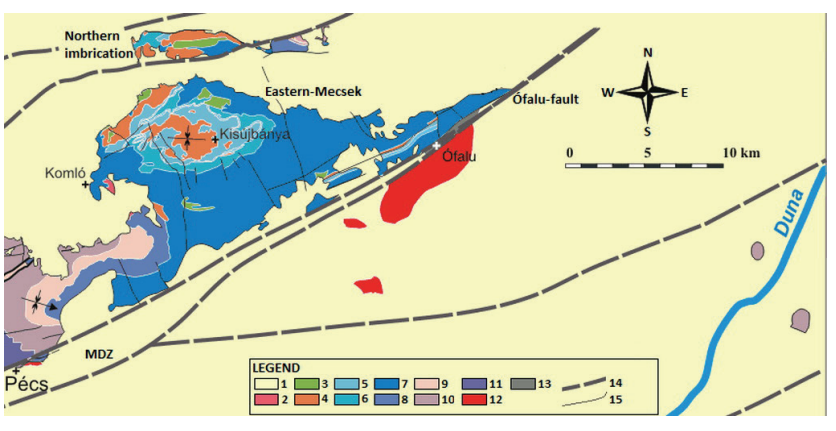

Fig. 2 Geological map of Eastern-Mecsek with the major tectonic features [20]. Legend: 1. Neogene-Quaternary sedimentary cover, 2. Miocene andesite, 3. Cretaceous sediments, 4. Cretaceous basalt, 5. Upper Jurassic sediments, 6. Middle-Upper Jurassic carbonates,

7. Lower, Middle Jurassic formations, 8. Upper Triassic - Lower Jurassic coal, 9. Upper Triassic clastic sediments, 10. Middle Triassic carbonates, 11. Lower-Middle clastics and evaporites, 12. Paleozoic granite, 13. Paleozoic metamorphic rocks, 14. major faults showing neotectonic activity as well, 15 . other tectonic features, MDZ-

Mecsekalja Dislocation Zone 
- Formation of the elongated shape pluton and magma mixing in the Palaeozoic.

- Variscan orogeny: The Formation suffered regional metamorphism reflected in ductile deformation structures (S1and S2 foliation, narrow mylonitic zones).

- Alpine orogeny: reverse faults, strike slips occurrence and intrusion of trachyte dykes due to the Cretaceous transpression and extensional deformation. The deformation events reflected by brittle deformation structures (open fractures, fractures with slickenlines, cataclasites).

- Transpressional displacement due to the regional rotation of the block in Miocene. In Late MiocenePliocene transpressional elevation, reactivation of former structures.

The Mórágy Granite was sampled from core rock recovery from numerous boreholes. The rock types of the observed samples are monzogranites with inequigranular poikilitic textures according to the petrographical thin section analysis. The samples contain mostly sub grained quartz with undulated extinction (about 20-30\%), feldspar (orthoclase and plagioclase, 35-45\%), biotite (10-15\%), and amphibole (less than $10 \%$ ) minerals. The biotite and amphibole (hornblende) crystals formed mafic aggregates. Accessories are the following: apatite, titanite, and zircon.

\section{Theoretical background of fracture propagation}

What's mean intact rock? From an engineering point of view the right answer is investigating laboratory scale rock samples example intact bored drill cores. For many rock types, the grain size is small enough that samples of this scale can be considered homogeneous and isotropic.

A number of stress states need to be considered and, as is common in most discussions on this topic, it will be assumed that these stress states can be considered in two dimensions.

In other words, it is assumed that the intermediate principal stress $\sigma_{2}$ has a minimal influence on the initiation and propagation of failure in the samples [21] (Fig. 3).

As we check the theoretical background, we have to make a stop at the Griffith's theory.

Griffith [22] proposed that the failure of brittle materials is governed by the initial presence of microcracks. Under uniaxial tension, the tensile strength predicted by the Griffith's theory (Eq. (1)).

$\sigma_{t}=\sqrt{\lambda \frac{E^{\prime} \gamma}{c}}$, where $E^{\prime}=E$ for plane stress problems and $E^{\prime}=E /\left(1-v^{2}\right)$ for plane strain problems and $E$ is the Young's modulus, $v$ is Poisson's ratio, $\gamma$ is the specific surface energy, $c$ is the half crack length, and $\lambda$ is a numerical constant $(\lambda=2 / \pi)$.

Other researchers summarized the brittle failure of rock materials by using other approach [23, 24]. The stresses induced around open penny-shaped cracks in a semi-infinite body subjected to triaxial compressive stresses $\sigma_{1}, \sigma_{2}$ and $\sigma_{3}$. It was shown that the intermediate principal stress $\sigma_{2}$ has no significant influence on the crack tip stresses inducing tensile failure initiation. Hence, this criterion is essentially equivalent to loading a penny-shaped crack in a biaxial stress field, as shown in Fig. 4.

\section{Measurement of the basic spalling parameters by using laboratory testing}

The excavation of an underground opening in a stressed rock mass results in the deformation of the near-field rock due to a redistribution of stresses, resulting in induced stress concentrations. The mentioned stress redistribution increases strain energy in zones of increased compression. If the
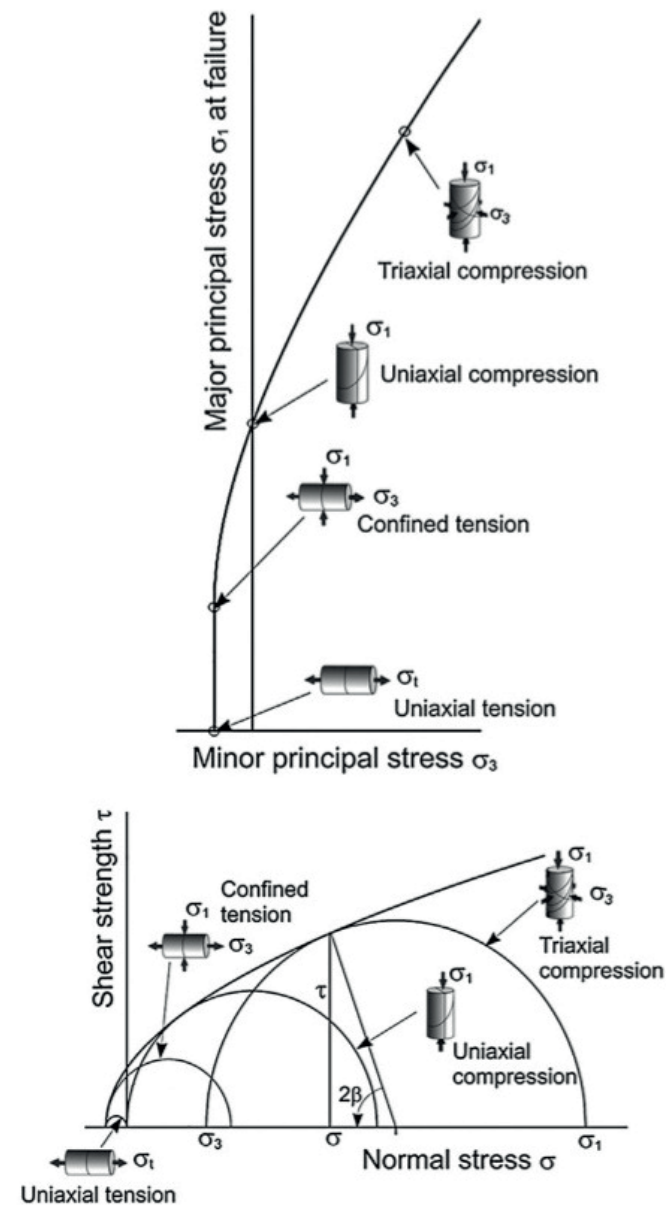

Fig. 3 Intact rock failure characteristics [21] 

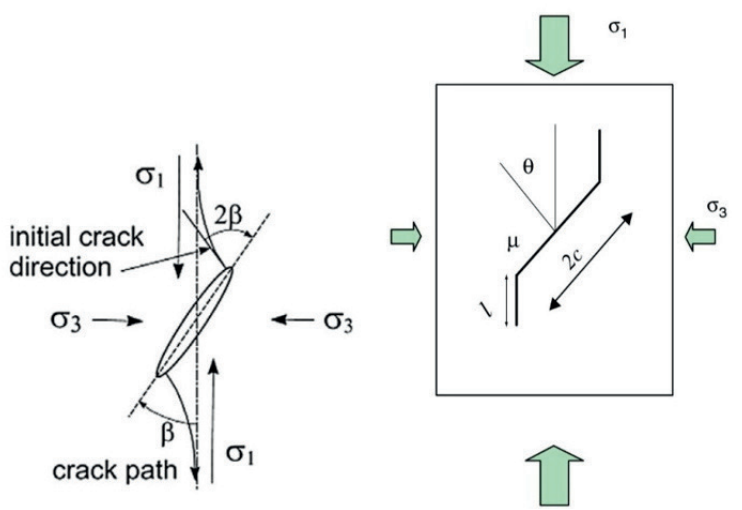

Fig. 4 Tensile crack propagation from an inclined elliptical Griffith crack in a biaxial stress field, after [21, 25]

resulting imbalance in the energy of the system is severe enough, it can result in the progressive degradation of the rock mass strength through fracturing. Hence it is important to establish the thresholds associated with microscale and macroscale fracturing in the in-situ rock mass.

Regarding to the brittle failure the most adequate theory was presented by Martin [26] (Fig. 5).

The most reliable methods are the crack volume strain method (with strain gauges) and the acoustic emission method (with $\mathrm{AE}$ transducers) for the determination of crack closure (CC), crack initiation (CI) and crack damage (CD) thresholds [27].

The damage thresholds were determined following the methods outlined by Eberhardt's and Martin's instructions $[26,28]$.

At the first investigation phase, from 208 UCS measurements using strain gauges we could use only 55 gave reliable strain results to determine the strength thresholds. This was because the strain gauges on the cores were damaged often before the failure of the samples.

To make possible the detection of the mentioned thresholds it is required the simultaneously functioning of the installed strain gauges at the $\mathrm{CD}$ boundary.

Based on the statistical analyses, a smaller range of values at $\mathrm{CC}$ and $\mathrm{CI}$ thresholds were observed. Typically, the CI threshold is $35-50 \%$ of UCS, while the CD is around $80 \%$ of UCS [27].

The summarized results show, that the monzogranite samples behaves as brittle material during the UCS laboratory tests (between the $\mathrm{CD}$ and failure stage rarely could be detected "creeping", or ductile indications).

Because of the sub-granular structure of the monzonite, it deforms ductile before the failure. This stage is somewhat larger than in the case of monzogranite. The results are summarized in Tables 1 and 2 [29].

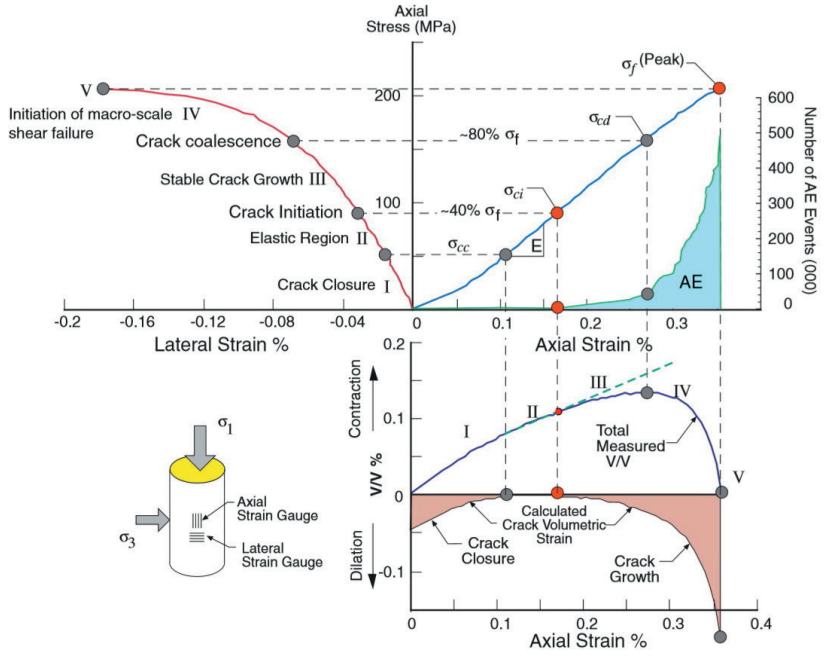

Fig. 5 Stress strain diagram of a granite (Lac du Bonnet) showing the stages of crack development [26]

Table 1 Damage thresholds for the monzogranite (36 samples)

\begin{tabular}{lcccc}
\hline Threshold & CC & CI & CD & UCS \\
\hline Mean (MPa) & 24.45 & 52.14 & 145.60 & 165.11 \\
Standard deviation & 4.50 & 10.65 & 17.09 & 19.25 \\
\% (of UCS) & 14.81 & 31.58 & 88.18 & - \\
\hline
\end{tabular}

Table 2 Damage thresholds for the monzonite (11 samples)

\begin{tabular}{lcccc}
\hline Threshold & CC & CI & CD & UCS \\
\hline Mean (MPa) & 24.22 & 53.30 & 134.25 & 163.72 \\
Standard deviation & 3.27 & 13.67 & 28.74 & 14.22 \\
\% (of UCS) & 14.79 & 32.55 & 82.00 & - \\
\hline
\end{tabular}

As second laboratory measuring method is the multistage triaxial testing which samples were studied by microscopic examinations together with the UCS tested samples.

During the tests, a rock specimen is inserted to a compressive stress state in which the maximum principal stress is increased at a constant rate and the other two principal stresses are by equal magnitude, i.e., $\sigma_{1}>\sigma_{2}=\sigma_{3}>0$, where positive stresses indicate compression. Although such a stress field is not particularly common in the subsurface, as is indicated by [30,31], it is commonly used in rock mechanics laboratories due to necessity which results from experimental restrictions.

According to the recommendations of the International Society for Rock Mechanics, there are three ways to carry out a conventional triaxial test, [32]: a.) the single stage triaxial test; b.) the multiple failure state triaxial test; and c.) the continuous failure stage test.

The presented failed sample was tested by the multiple state triaxial test method. 
With the single stage test, several triaxial tests are required in order to determine the strength envelope of a rock sample with satisfactory accuracy, over the required range of confining pressures, where the actual number of specimens needed depends on the intrinsic variability of the rock and the scatter of the data. As an alternative, a methodology was proposed by Kovari and Tisa [33], called the "Multiple Failure State Triaxial Test" (or simply the "multistage triaxial test"), in which, by using only one specimen, more than one stress points of the failure envelope are obtained.

The peak and the residual strength envelopes of our specimens were obtained and their strength parameters were determined through simple regression techniques.

The following figure (Fig. 6) summarize the HoekBrown failure envelopes of the first successful tested rock specimen group by multistage triaxial testing method. During the measurements we were using between 3 and 9 stages by changing the confinement stress [34]. Presently in the new investigation phases we are able to test the core samples until $40 \mathrm{MPa}$ confining pressure.

During the UCS and the triaxial tests were used strain gauges, in the future investigations will be added AE sensors for the better characterizing the failure behavior.

\section{Petrographical observations}

At this first microscopy stage the aim was to investigate the cracking mechanisms, crack initiation and the damage characteristics leading to failure. Thin sections were cut before and after the measured rock specimen failure and examined by petrological microscope.

The thin sections were prepared from the cut rock pieces from the rock cores axial and lateral planes.

The first sample, BeR-4_KV-001 was tested by using continuously $5 \mathrm{MPa}$ confining pressure and failed at $157 \mathrm{MPa}$.

The second sample, Bp-3_KV-031 was tested by using 3 confining pressure stages (Fig. 7).

The following figures (Figs. 8-14) show the results on the petrographic microscopy.

Thin sections prepared from the intact samples, contain some visible fractures which are infilled and appear prominently the schistosity as a trace of previous geological history (Fig. 8).

The thin section exposure has shown a slightly sheared, (mylonitic texture) monzogranite, consists of sub grained quartz crystal matrix, embedded anhedral, peripheral sub grained biotite augens due to the plastic deformations, rounded shape, euhedral potassium feldspar with sericite alteration and plagioclase crystal aggregate.

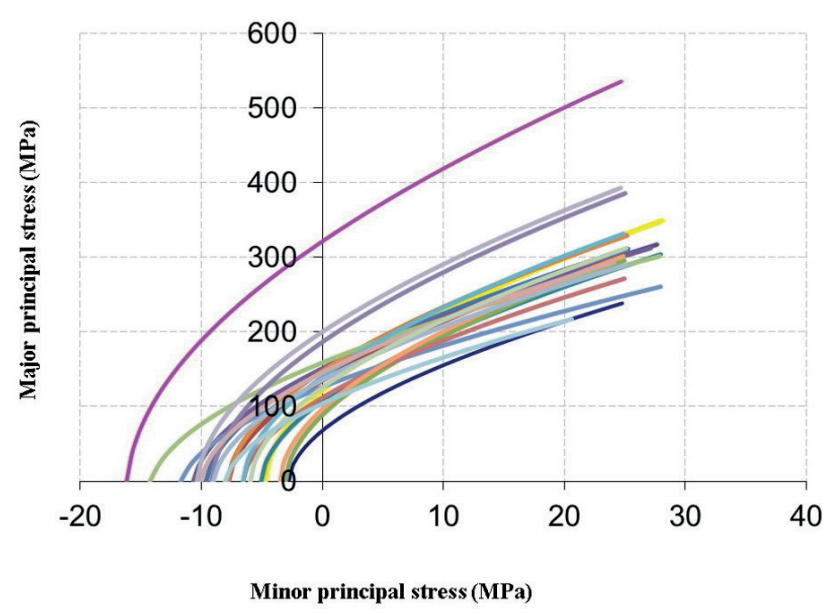

Fig. 6 Hoek-Brown failure envelopes of the tested rock core samples by using multistage triaxial method

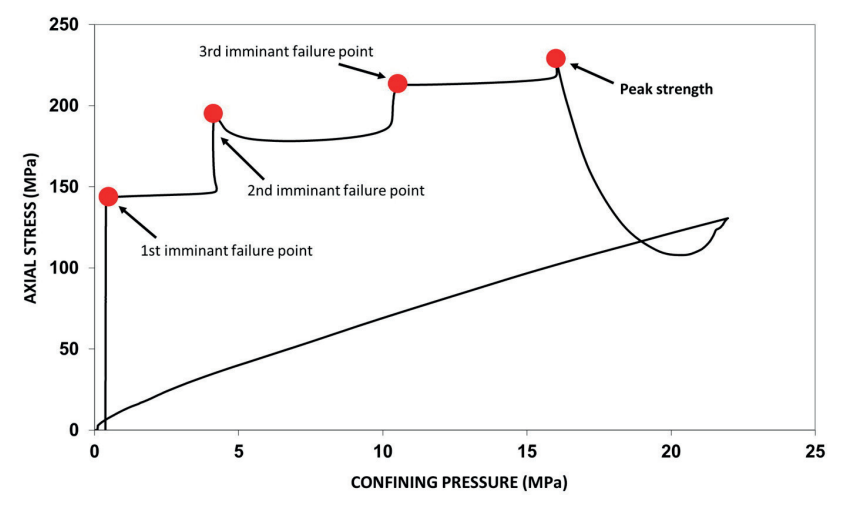

Fig. 7 Stress path of the Bp-3_KV-03 multistage triaxial test

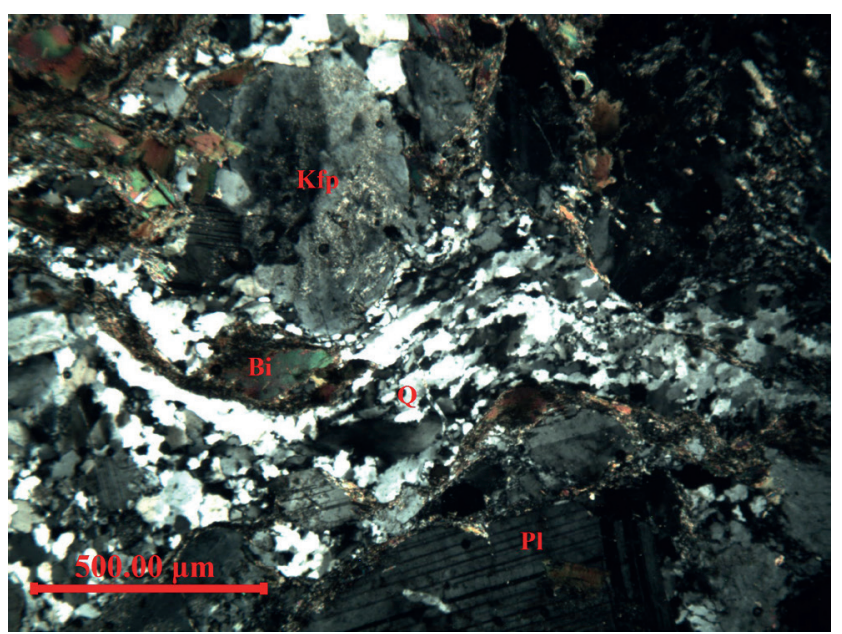

Fig. 8 Thin section prepared before the triaxial test - BeR-4_KV-001

In the microscopic photographs, two types of pre-existing cracks are observed, namely inter- and intra-granular cracks (Figs. 9 and 10).

Three types of intragranular cracks were observed, namely intra-granular veins, cleavages and micro-fissures. Numerous cracks filled with mica minerals were observed 


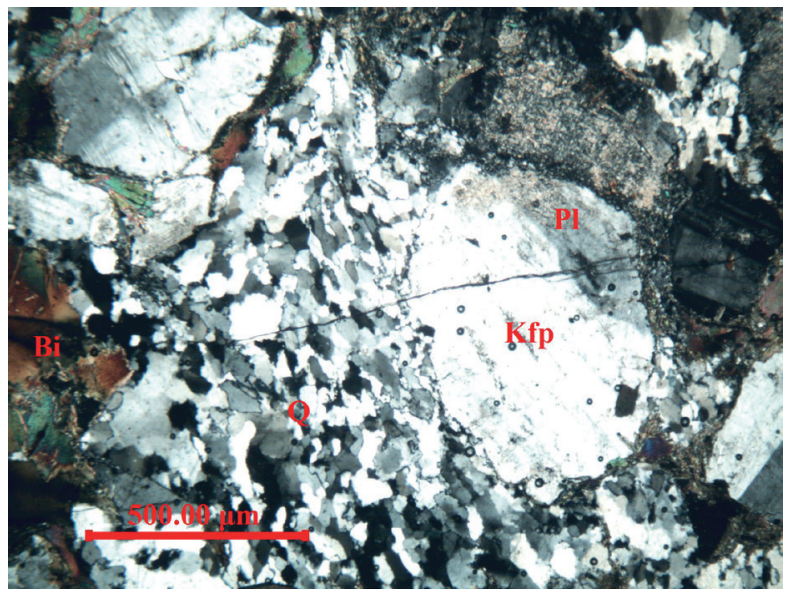

Fig. 9 Intragranular crack in the plagioclase crystal (crossed nikol) BeR-4 KV-001

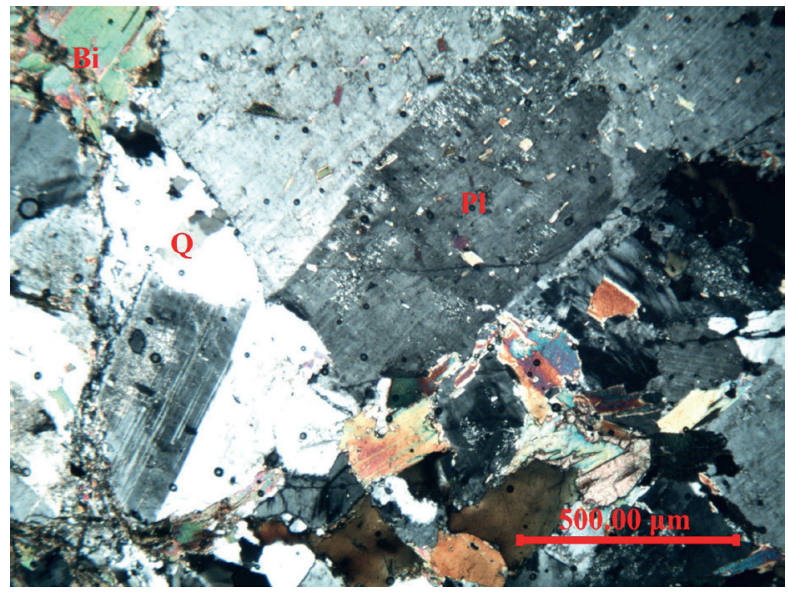

Fig. 10 Intergranular crack with the coalescence wing crack (crossed nikol) - BeR-4_KV-001

within the quartz grains and in the ultramafic minerals, suggesting that the specimens had a significant metamorphic history (Fig. 11).

Two types of stress-induced cracks were observed and grouped as follows:

- intergranular cracks, which initiate and propagate from the grain boundary,

- intra-granular cracks, which initiate and propagate within the mineral grain.

Under uniaxial loading conditions, once the stress concentration has overcome the interlocking cohesion in the grain boundaries between mineral grains or exceeded the tensile strength of mineral grains at the tip of cracks, sliding or crack initiation may occur [7]. Generally, cracking initiates at the most favorable angle where the highest stress concentration is induced. As observed in this study (Fig. 11), sliding may occur along the grain boundary below the crack initiation stress level. Afterwards cracking initiates and propagates into another mineral aligned with the loading direction at the higher stress level shows that cracking initiates and propagates from the grain boundary healed by mica minerals between quartz and plagioclase. According to Fig. 12, the crack is straight and becomes narrower as the crack propagates in the stress direction.

As it is observed, cracking is initiated in quartz and feldspar grains from the mica mineral-filled veins or from the pre-existent nucleation and propagates in the direction aligned to the principal stress (depending on the cut direction of the specimen, this is the axial or lateral stress direction) (Fig. 11). This crack resembles Griffith's crack, where cracking is initiated near the crack tip and out of the crack plane.

Cracking is initiated from the pre-existing intra-crystal crack or microfissure (Fig. 9). From the pattern of crack propagation from initial wing cracking (tensile cracking), progressive propagation of cracking with different phases of loading is clearly shown with a wider crack width narrowing down.

Two types of cracks have been regularly observed: primary cracks and secondary cracks. Primary cracks or Wing cracks appear first; they are tensile cracks which start at the tips of the flaw [11] and propagate in a curvilinear path as the load is increased. Wing cracks grow in a stable manner since an increase in load is necessary to lengthen the cracks, and align with the direction of the most compressive load [35]. Secondary cracks appear later and are responsible, in most cases, for specimen failure, they are described by many authors as shear cracks. Secondary cracks in most cases initiate in a direction coplanar to the flaw (pre-existing crack), although other researchers, such as $[8,36]$, have described other initiation directions. This appears to indicate that the direction of initiation of the secondary cracks may be material dependent. The preceding description must be viewed as a limited summary since there are other cracks which, although described by some researchers, are observed in the micrographs (Figs. 11, 12, 13, 14). For a detailed review of the types of cracks observed in uniaxial compression [11]. In multiple flaw systems under uniaxial loading, wing cracks and secondary cracks also occur and eventually lead to coalescence.

Wing cracks appear in all uniaxial compression tests and in biaxial compression tests at low confining stresses. Wing cracks emanate from the tips of the flaws, and propagate in a stable manner following a curvilinear path that aligns with the most compressive load. Wing cracks 


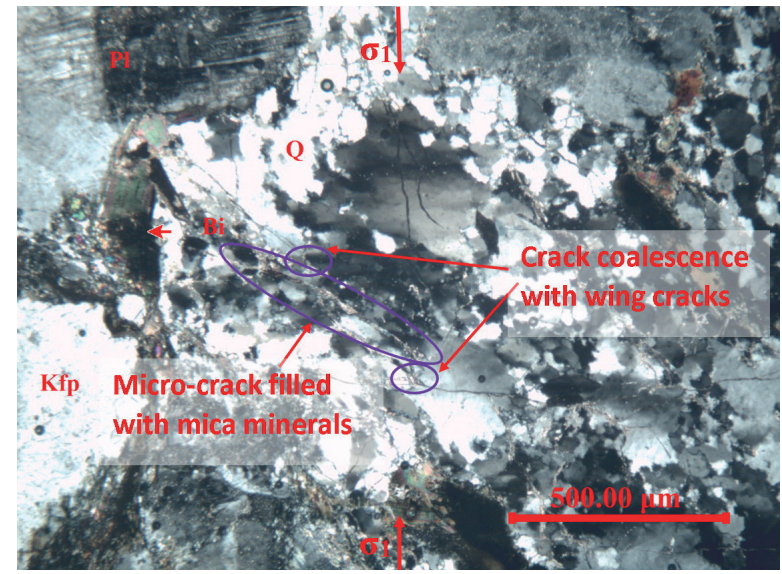

Fig. 11 Micro-cracks infilled with mica minerals (crossed nikol) Bp-3_KV_031

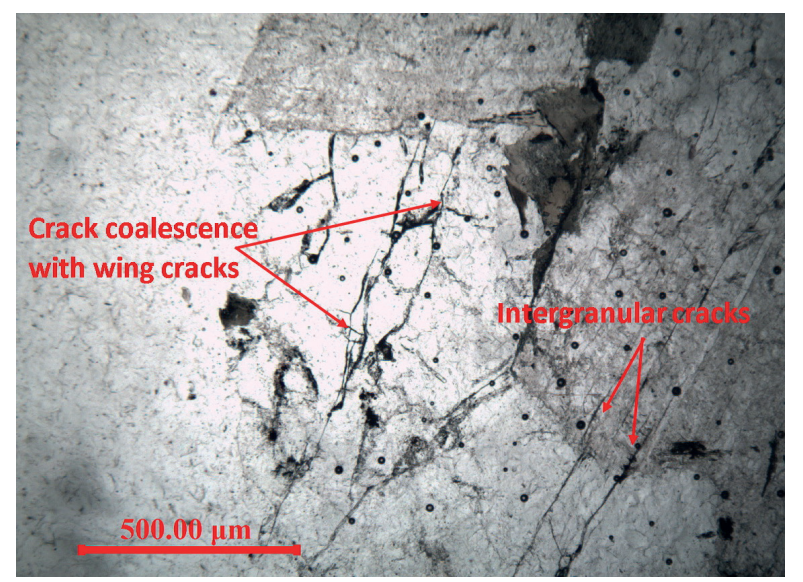

Fig. 13 Crack coalescence and wing cracks with non-overlapping flaw geometry (parallel nikol) - Bp-3_KV_031

propagate in a stable manner; i.e. the external load needs to be increased for the cracks to propagate further. Internal and external wing cracks, once produced, remain open up to coalescence or up to failure if there is no coalescence. If coalescence occurs, the internal wing cracks close at coalescence. In general, the external wing cracks are longer than the internal wing cracks; the external wing cracks can even reach the top and bottom boundaries of the specimen and cause failure, while the internal wing cracks are usually confined to the ligament area.

Lajtai [8, 36] found that fracture initiation greatly depends on the geometry of wing cracks, which is the term usually given to the tensile cracks that initiate at the points of maximum tensile stress concentration and propagate along a curvilinear direction that becomes roughly parallel to the far field compression (Fig. 15.(a)). In addition, secondary cracks also initiate from the flaw tips, similar to tensile crack initiation, except that the extended direction and stress level of initiation are determined by

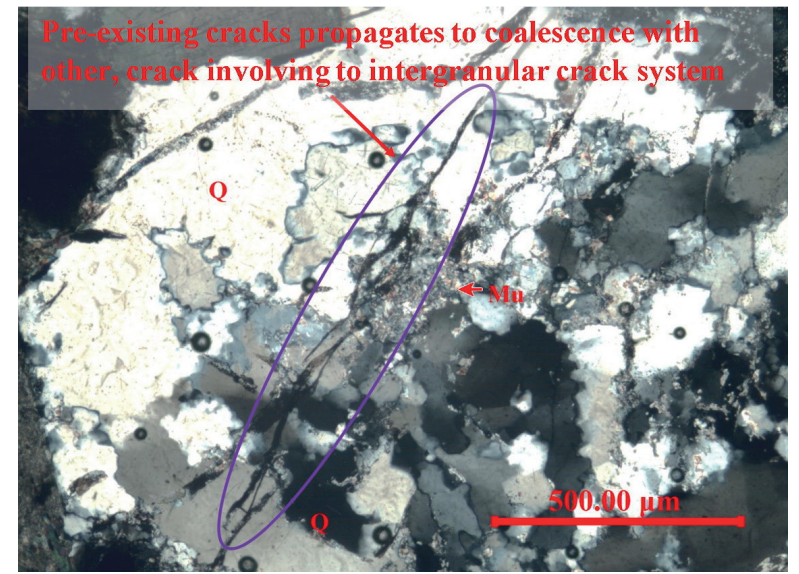

Fig. 12 Propagated and coalescence of pre-existing cracks, with overlapping geometry (crossed nikol) - Bp-3_KV_031

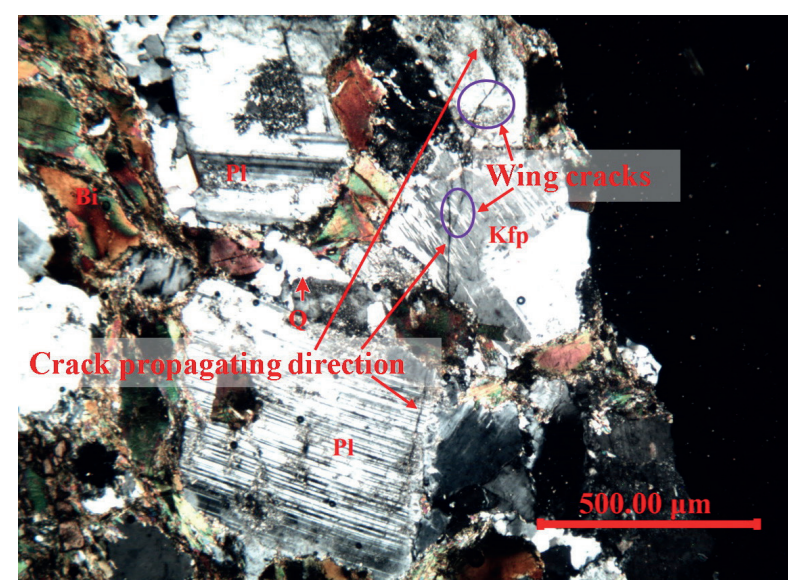

Fig. 14 Crack propagation and non-overlapping geometry (crossed nikol) - BeR-4_KV-001

the direction and magnitude of maximum shear [37]. A coalescence crack could be produced by a tensile crack or shear crack or mixed tensile and shear cracks [11]. The generation of shear fractures and tension fractures could be combined, which often marks the failure of a specimen. The relative positions of the pre-existing flaws play a significant role in crack coalescence. The cracks would interconnect in the propagation process if the pre-existing flaws overlap, as presented in Fig. 15.(a). In [10] results indicate that the position where the wing crack initiates also depends on the magnitude of confining stress that transits from the flaw tip to the middle of the flaw and finally disappears with increasing confinement.

The research on crack propagation and coalescence from microscopic to macroscopic scale in gypsum and Carrara marble specimens with one and two pre-existing flaws was conducted by Wong and Einstein 0, [40]. The coalescence type was related to bridge length, bridge angle and flaw inclination angle (Fig. 15.(b)). 


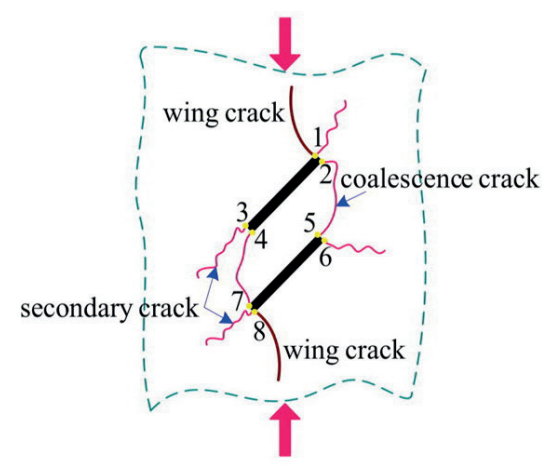

a.

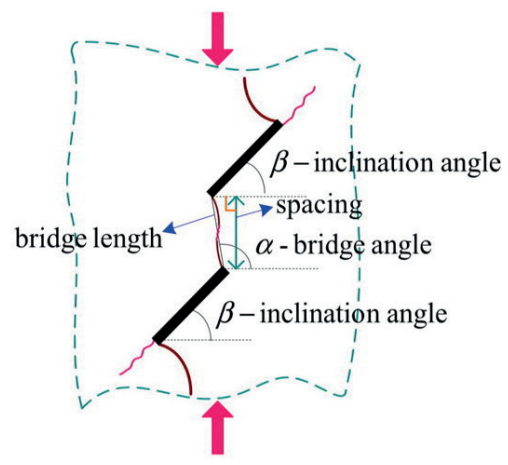

b.

Fig. 15 Crack pattern in brittle specimen with parallel and overlapping (a.) or non-overlapping (b.) pre-exiting flaws in uniaxial compression. Tips 3-6 are internal tips, and tips 1, 2, 7 and 8 are external tips [38]

Numerous studies mainly concentrate on the pre-existing flaws that completely penetrate the (two dimensional) specimen. Less work has been done on crack growth from pre-existing flaws that do not penetrate completely through the specimen, which is a more complicated non-planar problem. Teng [41] found that crack growth from non-penetrating flaws is spiral and not coplanar to the initial flaws. 3D wing cracks were studied by [42, 43], in which the growth of wing cracks from pre-existing flaws was influenced by their shape, location and spacing.

In our thin sections are not clearly visible this phenomenon as regularly in case of planar observations. But the previously mentioned parallel, overlapping and non-overlapping flaws (or pre-existing cracks) are presents in the Figs. 12-14.

In [44], the numerically simulated results demonstrated that rock heterogeneity and inclination of the pre-existing flaw are important factors that could affect the crack patterns and peak uniaxial compressive strength of rock specimens. To investigate the propagation and coalescence of nonpenetrating surface flaws and their effect on the strength of soft rock material, gypsum was selected for the experimental investigation.

\section{Conclusions}

In this laboratory study, uniaxial and triaxial compression tests were carried out.

As a detailed investigation, a comprehensive petrographical analysis using a petrological microscope was

\section{References}

[1] Griffith, A. A. "The phenomena of rupture and flow in solids", Philosophical Transactions of the Royal Society A, Mathematical, Physical and Engineering Sciences, 221(582-593), pp. 163-198, 1921. https://doi.org/10.1098/rsta.1921.0006 performed to identify the mode of cracking and the characterization of the cracking pattern on the UCS and triaxial laboratory tested specimens.

The cut samples for the thin sections were prepared from the intact and failed tested rock core samples. In the thin sections prepared from the intact samples, were identified only mica infilled previous cracks and appears prominently the schistosity as a trace of previous geological history. For the used intermediate stress states during the laboratory tests, no sample collection was performed.

In the MGF granitic thin section specimens were definitely identified the flaws (initial cracks) and the wing cracks. Secondary cracks were observed less frequently.

Two types of pre-existing cracks are observed under the petrological microscope, inter- and intra-granular cracks.

Under optical watching the development of flaws (or preexisting cracks) found to be more complicated than in the simplified laboratory tests by using gypsum material, which were found in the literature. Even so coalescence of wing cracks with different isolated cracks or crack systems might be the main source of the smashing and failure of specimen.

As further investigation it is planned to be collected and prepared thin sections from tested UCS rock core specimens by using strain gauges and AE sensors [45]. For the complex microscopic investigation of the cracking behavior, samples will be collected from the different crack development stages: intact, crack initiation (CI), crack damage (CD) and UCS (or failure).

[2] McClintock, F. A., Walsh, J. B. "Friction on Griffith cracks in rock under pressure", In: Proceedings of the 4th U.S. National Congress on Applied Mechanics, Berkley, CA, USA, 1962, pp. 1015-1021. 
[3] Brace, W. F. "Brittle fracture of rocks", In: Proceedings of the International Conference on the State of Stress in the Earth's Crust, Santa Monica, CA, USA, 1964, pp. 111-178.

[4] Bieniawski, Z. T. "Mechanism of brittle fracture of rock", Part I - theory of the fracture process", International Journal of Rock Mechanics and Mining Sciences \& Geomechanics Abstracts, 4(4), pp. 395-404, 1967.

https://doi.org/10.1016/0148-9062(67)90030-7

[5] Brace, W. F., Bombolakis, E. G. "A note on brittle growth in compression", Journal of Geophysical Research, 68(12), pp. 3709-3713, 1963. https://doi.org/10.1029/JZ068i012p03709

[6] Hoek, E., Bieniawski, Z. T. "Brittle fracture propagation in rock under compression", International Journal Fracture Mechanics, 1, pp. 137-155, 1965. [online] Available at: https://link.springer.com/ article/10.1007/BF00186851 [Accessed: 20 December 2020]

[7] Hoek, E. "Brittle fracture of rock" In: Stagg, K. G., Zienkiewicz, O. C. (eds.) Rock Mechanics in Engineering Practice", Wiley, London, UK, 1968, pp 4-92.

[8] Lajtai, E. Z., Lajtai, V. N. "The evaluation of brittle fracture in rocks", Journal of the Geological Society, 130, pp. 1-16, 1974. https://doi.org/10.1144/gsjgs.130.1.0001

[9] Reyes, O., Einstein, H. H. "Failure mechanisms of fracture rock", In: Proceedings of the 7th U.S. National Congress of Applied Mechanics, Boulder, CO, USA, 1991, pp. 333-340.

[10] Shen, B. "The mechanism of fracture coalescence in compression - experimental study and numerical simulation", Engineering Fracture Mechanics, 51(1), pp. 73-85, 1995. https://doi.org/10.1016/0013-7944(94)00201-R

[11] Bobet, A., Einstein, H. H. "Fracture coalescence in rock-type materials under uniaxial and biaxial compression", International Journal of Rock Mechanics and Mining Sciences, 35(7), pp. 863888, 1998.

https://doi.org/10.1016/S0148-9062(98)00005-9

[12] Brady, B. H. G., Brown, E. T. "Rock mechanics for underground mining", 2nd ed. Chapman and Hall, Australia, pp. 345-398, 1994.

[13] Zare, M., Deák, F. "The examination of a recently proposed model solution for shearbehaviour of infilled natural rock joints based on multi-scalelaboratory investigations", In: Ulusay, R., Aydan, O., Gercek, H., Hindistan, M. A., Tuncay, E. (eds.) Rock Mechanics and Rock Engineering: From the Past to the Future, Taylor \& Francis Group, London, UK, 2016, pp. 359-364.

[14] Császár, G. "Alpine burial history of the Mórágy Block and its environs", In: Annual Report of the Geological Institute of Hungary, Geological Institute of Hungary, Budapest, Hungary, 2004, pp. 395-401. [online] Available at: https://epa.oszk.hu/02900/02934/ 00030/pdf/EPA02934_mafi_evi_jelentes_2003_395-401.pdf [Accessed: 20 December 2020]

[15] Marsi, I., Don, Gy., Földvári, M., Koloszár, L., Kovács-Pálffy, P., Krolopp, E., Lantos, M., Nagy-Bodor, E., Zilahi-Sebess, L. "Quaternary sediments of the north-eastern Mórágy Block", In: Annual Report of the Geological Institute of Hungary, Geological Institute of Hungary, Budapest, Hungary, 2004, pp. 343-359. [online] Available at: https://epa.oszk.hu/02900/02934/00030/pdf/ EPA02934_mafi_evi_jelentes_2003_361-369.pdf [Accessed: 20 December 2020] (in Hungarian)
[16] Balla, Z. "Pannonian sediments of the north-eastern Mórágy Block", In: Annual Report of the Geological Institute of Hungary, Geological Institute of Hungary, Budapest, Hungary, 2004, pp. 333337. [online] Available at: https://epa.oszk.hu/02900/02934/00030/ pdf/EPA02934_mafi_evi_jelentes_2003_333-337.pdf [Accessed: 20 December 2020]

[17] Király, E., Koroknai, B. "The magmatic and metamorphic evolution of the north-eastern part of the Mórágy Block", In: Annual Report of the Geological Institute of Hungary, Geological Institute of Hungary, Budapest, Hungary, 2004, pp. 299-310. [online] Available at: https://epa.oszk.hu/02900/02934/00030/pdf/ EPA02934_mafi_evi_jelentes_2003_299-310.pdf [Accessed: 20 December 2020]

[18] Maros, Gy., Koroknai, B., Palotás, K., Fodor, L., Dudko, A., ForiánSzabó, M., Zilahi-Sebess, L., Bán-Győry, E. "Tectonic analysis and structural evolution of the north-eastern Mórágy Block", In: Annual Report of the Geological Institute of Hungary, Geological Institute of Hungary, Budapest, Hungary, 2004, pp. 371-386. [online] Available at: https:/epa.oszk.hu/02900/02934/00030/pdf/ EPA02934_mafi_evi_jelentes_2003_371-386.pdf [Accessed: 20 December 2020]

[19] Varga, A., Szakmány, Gy., Árgyelán, T., Józsa, S., Raucsik, B., Máthé, Z. "Complex examination of the Upper Paleozoic siliciclastic rocks from southern Transdanubia, SW HungaryMineralogical, petrographic, and geochemical study", In: Sedimentary Provenance and Petrogenesis: Perspectives from Petrography and Geochemistry, 420, Geological Society of America, Boulder, CO, USA, 2007, pp. 221-240.

https://doi.org/10.1130/2006.2420(14)

[20] Konrád, Gy., Sebe, K., Halász, A., Halmai, Á. "A DélkeletDunántúl földtani fejlődéstörténete - recens analógiák", Földrajzi Közlemények, 134(3), pp. 251-265, 2010. [online] Available at: https://www.foldrajzitarsasag.hu/downloads/foldrajzi_kozlemenyek_2010_134_evf_3_szam. pdf [Accessed: 20 December 2020] (in Hungarian)

[21] Hoek, E., Martin, C. D. "Fracture initiation and propagation in intact rock - A review", Journal of Rock Mechanics and Geotechnical Engineering, 6(4), pp. 287-300, 2014.

https://doi.org/10.1016/j.jrmge.2014.06.001

[22] Griffith, A. A. "Theory of rupture", In: Proceedings of the 1st International Congress of Applied Mechanics, Delft, Netherlands, 1925, pp. 55-63.

[22] Andreev, G. E. "Brittle failure of rock materials", Balkema, Rotterdam, Netherlands, 1995.

[23] Paterson, M. S. "Experimental Rock Deformation - The Brittle Field", Springer, Berlin, Heidelberg, Germany, 2005. https://doi.org/10.1007/978-3-662-11720-0

[24] Cai, M. "Practical Estimates of tensile Strength and Hoek-Brown Strength Parameter $m_{i}$ of Brittle Rocks", Rock Mechanics and Rock Engineering, 43, pp. 167-184, 2010. https://doi.org/10.1007/s00603-009-0053-1

[25] Martin, C. D. "The Strength of Massive Lac du Bonnet Granite Around Underground Opening", Ph.D. thesis, University of Manitoba, 1993. [online] Available at: http://hdl.handle. net/1993/9785 [Accessed: 20 December 2020] 
[26] Diederichs, M.S., Martin, C. D. "Measurement of spalling parameters from laboratory testing", In: Zhao, J., Labiouse, V., Drudt, J.-P., Mathier, J.-F. (eds.) Rock Mechanics in Civil and Environmental Engineering, CRC Press, London, UK, pp. 2010, 323-326.

[27] Eberhardt, E., Stead, D., Stimpson, B., Read, R. S. "Identifying crack initiation and propagation thresholds in brittle rock", Canadian Geotechnical Journal, 35(2), pp. 222-233, 1998. https://doi.org/10.1139/t97-091

[28] Deák, F., Kovács, L., Vásárhelyi, B. "Modeling the Excavation Damaged zones in the Bátaapáti radioactive waste repository", In: EUROCK2013, London, UK, 2013. pp. 603-608. https://doi.org/10.1201/b15683-101

[29] Jaeger, J. C., Cook, N. G. W., Zimmerman, R. W. "Fundamentals of Rock Mechanics", 4th ed., Wiley-Blackwell, Oxford, UK, 2007.

[30] Deák, F., Ván, P., Vásárhelyi, B. "Hundred years after the first triaxial test", Periodica Polytechnica, Civil Engineering, 56(1), pp. 115-122, 2012. https://doi.org/10.3311/pp.ci.2012-1.13

[31] Kovari, K., Tisa, A., Einstein, H. H., Franklin, J. A. "Suggested methods for determining the strength of rock materials in triaxial compression: Revised version", International Journal of Rock Mechanics and Mining Sciences \& Geomechanics Abstracts, 20(6), pp. 283-290, 1983. https://doi.org/10.1016/0148-9062(83)90598-3

[32] Kovári, K., Tisa, A. "Multiple Failure State and Strain Controlled Triaxial tests", Rock Mechanics, 71, pp. 17-33, 1975. https://doi.org/10.1016/0148-9062(75)90403-9

[33] Vásárhelyi, B., Kovács, L., Kovács, B. "Determening the failure envelope of the intact granitic rocks from Bátaapáti", Geosciences and Engineering, 2(4), pp. 93-101, 2013.

[34] Vásárhelyi, B., Bobet, A. "Modeling of Crack Initiation, Propagation and Coalescence in Uniaxial Compression", Rock Mechanics and Rock Engineering, 33, pp. 119-139, 2000. https://doi.org/10.1007/s006030050038

[35] Lajtai, E. Z. "A theoretical and experimental evaluation of the Griffith theory of brittle fracture", Tectonophysics, 11(2), pp. 129156, 1971. https://oi.org/10.1016/0040-1951(71)90060-6

[36] Bobet, A. "The initiation of secondary cracks in compression", Engineering Fracture Mechanics, 66(2), pp. 187-219, 2000. https://doi.org/10.1016/S0013-7944(00)00009-6
[37] Xu, J., Zheng, Z., Xiao, X., Li, Z. "Crack propagation and coalescence due to dual non-penetrating surface flaws and their effect on the strength of rock-like material", Journal of Geophysics and Engineering, 15(3), pp. 938-951, 2018.

https://doi.org/10.1088/1742-2140/aaa985

[38] Wong, L. N. Y., Einstein, H. H. "Crack coalescence in molded gypsum and Carrara marble: I. Macroscopic observations and interpretation", Rock Mechanics and Rock Engineering, 42, pp. 475-511, 2009. https://doi.org/10.1007/s00603-008-0002-4

[39] Wong, L. N. Y., Einstein, H. H. "Crack coalescence in molded gypsum and Carrara marble: II. Microscopic observations and interpretation", Rock Mechanics and Rock Engineering, 42, pp. 513-545, 2009. https://doi.org/10.1007/s00603-008-0003-3

[40] Teng, C.-K., Yin, X.-C., Li, S.-Y., Cai, D.-E. "Experimental study of three dimensional fracture in plate specimens with nonpenetrating crack", Acta Geophysical Sinca, 30(4), pp. 371-378, 1987. (in Chinese)

[41] Dyskin, A. V., Germanovich, L. N., Ustinov, K. B. "A 3D model of wing crack growth and interaction", Engineering Fracture Mechanics, 63(1), pp. 81-110, 1999. https://doi.org/10.1016/S0013-7944(96)00115-4

[42] Dyskin, A. V., Sahouryeh, E., Jewell, R. J., Ustinov, K. B. "Influence of shape and locations of initial 3-D cracks on their growth in uniaxial compression", Engineering Fracture Mechanics, 70(15), pp. 2115-2136, 2003. https://doi.org/10.1016/S0013-7944(02)00240-0

[43] Liang, Z. Z., Xing, H., Wang, S. Y., Williams, D. J., Tang, C. A. "A three-dimensional numerical investigation of the fracture of rock specimens containing a pre-existing surface flaw", Computers and Geotechnics, 45, pp. 19-33, 2012. https://doi.org/10.1016/j.compgeo.2012.04.011

[44] Lee, B., Rathnaweera, T. D. "Stress threshold identification of progressive fracturing in Bukit Timah granite under uniaxial and triaxial stress conditions", Geomechanics and Geophysics for GeoEnergy and Geo-Resources, 2, pp. 301-330, 2016. https://doi.org/10.1007/s40948-016-0037-z 